\title{
CURRENT TRENDS IN CRITICAL LIMB ISCHEMIA - REVIEW
}

\begin{tabular}{ll} 
General Surgery & \\
$\begin{array}{ll}\text { Dr Puneet Kumar } \\
\text { Agarwal }\end{array}$ & MS(General Surgery),FMAS,FICRS Associate Professor Dept of Surgery, AIIMS Bhopal \\
\hline $\begin{array}{ll}\text { Dr Vikram } & \text { MS(General Surgery),Senior Resident Dept of Surgery, AIIMS Bhopal } \\
\text { Vasuniya * } & * \text { Corresponding Author }\end{array}$ \\
\hline
\end{tabular}

\section{ABSTRACT}

Critical limb ischemia (CLI) is considered the most severe clinical manifestation of peripheral artery disease (PAD). These patients carry high risk of amputation and mortality. CLI patientfaces may problems like restriction of movement, starvation of services and depression. Therapeutic goals in treating these patients include relieving ischemic pain, reducing cardiovascular risk factors, preventing major amputation, improving quality of life and increasing survival.Revascularization is the primary treatment strategy in critical limb ischemia patients. Many patients are not treatable by conventional techniques. This review article provides a comprehensive summary that includes current trends in the management of Critical limb ischemia like endovascular revascularization, gene and cell based therapies and drug eluting stents (DESs) etc.

\section{KEYWORDS}

Critical, limb, ischemia, current, trends

\section{INTRODUCTION}

Critical limb ischemia is (CLI) a most severe stage of peripheral arterial disease (PAD) resulting from impaired circulation to the lower limbs. It can be defined as $>2$ weeks of rest pain, ulcers or loss of tissue. CLI carries a $25 \%$ risk of mortality and another $25 \%$ risk of amputation over the next year [1].According to the Global Burden of Disease study approx 202 million adults worldwide have Peripheral arterial disease [2].Although most of them are asymptomatic but if left untreated, increases the risk of cardiovascular events, amputation and death. Approximately 1-3\% patients of PAD may present with Critical limb ischemia (CLI); these estimates are likely to increase as life expectancy, prevalence of diabetes, obesity and sedentary lifestyles are increasing [3-4]. Many of them present to the health care facility very late when the arteries are severely damaged.In many centers, amputation without revascularization is continued to be performed. Therapeutic goals in treating these patients include curtailing known etiologic factors, relieving ischemic pain, reducing cardiovascular risk factors, healing ulcers, preventing major amputation, improving quality of life and increasing survival. These aims may be achieved through medical therapy, revascularization, or amputation [1]

\section{DIAGNOSIS AND ASSESSMENT}

CLI is primarily a clinical diagnosis. Any of the ' $6 \mathrm{P}$ ' arises suspicion of ALI i.e. pain, pallor, paralysis, paresthesia, pulse deficit and poikilothermia. ALI can be classified on the basis of symptoms of limb ischemia by Fontaine or Rutherford classification. The holistic approach is to be taken to evaluate peripheral pulses and identify cardiovascular risk factors. Variousexaminations are helpful like ankle-brachial index (ABI), Toe-brachial index (TBI), transcutaneous partial pressure of oxygen ( $\mathrm{TcPO} 2)$, ankle systolic pressure and ultrasound color duplex scan.To demonstrate location and degree of arterial obstruction, Digital-subtraction angiography, computed tomo graphic angiography (CTA) and magnetic resonanceangiography (MRA) plays an important role.

\section{HOLISTIC MANAGEMENT OF CLI}

Treatment goals in the management of CLI includes relieving ischemicpain, optimization of cardiovascular risk factors,ulcer healing, improve limb perfusion, prevent further deformity by which improving quality of life and patient survival. These goals can be achieved by curtailing known etiologic factors, patient care, medical therapy, revascularization and amputation.

\section{Wound care and risk factor modification}

Initial treatment includes relieving of pain, which mayrequire narcotics, ulcer care, sheepskin bootsto increase superficial collateral supply, and tilting thepatient's bed downward which is required to keep limbin dependent position and so is to increase perfusion.[5]Relieving of pain is essential to improve quality of life and mobility. Usually, NSAIDs and paracetamol is used to relieve pain. Sometimes opiods are also needed. Wound care includes cleaning and dressing, treating infection, avoiding pressure over wound, improving nutrition and debridement, if necrosis developed in the wound. Local application of platelet-derived growth factor helps in the healing of chronic ulcer. The Sheepskin (Rooke) boots help to improve superficial collateral flow of limbs by increasing the local temperature.[6] Cessation of smoking, control of hypercholesterolemia \& hypertension must be ensured in these patients with strict glycemic control to achieve cardio protection.

\section{Medical Therapy}

In CLI patients coexisting cerebrovascular and coronary artery disease (CAD)accounts for considerable mortality and morbidity; hence, optimization of these risk factors is of primeimportance in the management of CLI patients. Medicaltherapy is primarily used to optimize these cardiovascular risk factors. [7].Various CLI guidelines consider the effectiveness of antiplatelet therapy, statins and ACEinhibitors to reduce cardiovascular events and mortality. Aspirin or clopidogrel is indicated for secondary prevention in patients with PAD and other cardiovascular diseases. Low dose of aspirin (75-160 $\mathrm{mg}$ ) is safe and effective.[8]Monotherapy with P2Y12 inhibitors viz. clopidogrel and ticagrelor has been studied in the context of single antiplatelet therapy for symptomatic PAD. Dual antiplatelet therapy (aspirin+clopidogrel or ticlopidine) is recommended in diabetic patientswho undergo lower limb revascularizationfor at least 1 month after endovascular procedure; after1 month, aspirin or clopidogrel should be continue lifelong.[9]In patients with CLI ,Cilastazol (phosphodiesterase III inhibitor having antiplatelet, antimitogenic and vasodilator properties) hasbeen shown to favorably increase skin perfusion pressureand wound healing.[10] Cilostazol (100 $\mathrm{mg}$ orally 2 times per day) is indicated in patients of PAD with intermittent claudication as an effective therapy to improve symptoms and increase walking distance. Due to the increased risk of bleeding, most surgeons reserve anticoagulation therapy for graft thrombosis or hypercoagulable disorders.

\section{Endovascular Revascularization}

Endovascular revascularization is the favoredapproach to CLI in many centers because of lower morbidity and mortalitythan open surgery. It aims to re-establish continuous in line pulsatile flow to the pedal arch and to reduce the surgery related complications without affectingthe limb salvage rate.Various patient and procedurespecific factorssuch as age and associated co-morbidity, vascular anatomy,severity of the ischemia, presenceof useable vein graft andextent of involvement determines choice between surgical versus endovascular treatment.This minimally invasivetreatment option has significantly evolved over thepast decades. Today many revascularization modalities is being practiced like plain balloon orpercutaneous transluminal angioplasty (PTA), several novelendovascular approaches and devices have been releasedon the market for example, stent-grafts bare metal stents, atherectomy devices, cryoplasty,, drugeluting stents, anddrug-eluting balloons.[11]PTA involves placing a wire intra-luminally beyond the lesion of interest and then expanding the inserted balloon at the lesion with the appropriate pressure which 
leads to fracture of the lesion and stretching of the arterial wall.The Bypass versus Angioplasty in Severe Ischemia of theLeg (BASIL) study was a randomized controlled trial that compared percutaneous transluminal angioplasty(PTA) with bypass surgery in 452 patients presenting with CLI.[12]According to this study, amputation-free survival, was similar forPTA and bypass surgery at 1 year (71\% vs. $68 \%, \mathrm{P}=\mathrm{NS})$ and 3 years $(52 \%$ vs. $57 \%, \mathrm{P}=\mathrm{NS})$. Surgery was associated witha higher post-procedure morbidity with no significant differencein mortality at 30 days.Usually,in patients of CLI with active co-morbidities, planned for angioplasty does not requiregeneral anesthesia. Percutaneous transluminal angioplasty (PTA) can be performed in patients not fit forbypass procedure, like in the presence of several co-morbidities, unavailability of veins, reducedlife expectancy ,absence of appropriate site for distal bypass and infection of the foot at the site ofpotential anastomosis.

\section{Surgical Revascularization}

It includes; Balloon catheter thrombectomy, Endarterectomy with or without patch angioplasty and Intraoperative isolated limb thrombolysis. The aims of surgical revascularization are to provide straightlineflow into the foot arch. The risk of perioperativemyocardial infarction (MI), death, and stroke are higher in open surgery than endovascularrevascularization. Surgical revascularization is advocated for the lesions that are not amenable to catheter-based intervention and in cases of younger patients with prolonged life expectancy who require a more durable revascularization.In case of long occlusion of femoro-popliteal and infra poplitealvessels, bypass is usually more effective and ensures patency of long segment. These aortoiliac diseases may be treatedwith anatomic or extra-anatomic bypass (e.g. axillobifemoral, axillofemoral, or femorofemoral bypass). Extra-anatomic repair are generally done in Patients who are older, more likely to have advanced ischemia, previous aorto-femoral inflow operation, renal insufficiency, and severe chronicobstructive pulmonary disease (COPD).[13]

\section{Hybrid Revascularization}

Hybrid revascularization refers to the combination ofopen surgery and endovascular approach that achieves complete revascularization with decreasedcomplications. Some patients of CLI might not benefit completely from percutaneous endovascular revascularization due to difficult access to the lesion or complex anatomy.These patients need hybrid therapy to achieve completerevascularization. Some of the advantages of this therapy are low risk compared to open surgery, less invasive technique, decreased complications and shorter duration of operation.[14-16] According to a study, 125 patients underwenthybrid therapy for de novo arterial reconstructionor revision of a bypass graft in which the perioperativemortality was $<1 \%$ and morbidity was $15.4 \%$.After follow-up over 27.6 months, the primary patency was $39.6 \%$, primaryB assisted patency $65.1 \%$, and secondary patency $73.5 \%$. [17].

\section{Amputation}

Amputations are to be reserved for patients unfit for surgical revascularization with no endovascular options available. Prior to concluding major amputations (at or above the knee), efforts should be made tosalvage the ischemic limb using surgery or endovascular techniques. Adequate blood supply is needed into the foot to maximize healing inminor amputations like toe, metatarsal or transmetatarsal. After the major amputations (at or above the knee), prosthesis is required and it limits functional independence.Due to Poor perfusion and healing,Up to one third of below-knee amputationsmay require further surgery/revision surgery or an above-knee amputation.[18] While taking decision of amputation, efforts shouldbe made to preserve knee joint because compared to above knee amputation, below knee amputation isassociated with reduced 30day mortality $(5 \%$ versus $16 \%)$ and increased longterm survival rate $(74.5 \%$ versus $50.6 \%$ ) [19-20]Bilateral amputation or above-knee amputation, dementia, increasing age are some of the factors related to poor prosthesis use.

\section{Evolving treatment options}

Gene and cellbased therapies are emerging treatment options in CLI management. These therapies are the new hope for nonrevascularizable patients and showed promising results by inducing local angiogenesis and neovascularization.Various gene therapies viz.fibroblast growth factor(FGF), hypoxia inducible factor 1, vascular endothelial growthfactor(VEGF), hepatocyte growthfactor and hypoxia inducible factor 1 have been tried.Out of these,hepatocyte growthfactor seems the most promising. Cell based therapies are bone marrow mononuclear cells,mesenchymal stem cells, and endothelial progenitor cells. Bone marrow-mononuclear cells were studied in a randomized, placebo controlledstudy, in which these cells were injected into the gastrocnemius muscle in 45 CLI patients. Significant improvements were noted at 4 weeks in terms of rest pain scale, $\mathrm{TcPO} 2, \mathrm{ABI}$, and pain-free walking time. It was observed that number of collaterals was increased compared to baseline in 27 of 45 patients, as evident by the Angiographic evaluation. [21]

The results of both the gene and cell based therapies are encouraging in the management of CLI. More double blinded control studies are needed to be done to evaluate long term outcome in terms of amputation, healing of wound and quality of life.Stenting: Restenosis significantly affects outcomes after PTA done. Stent placement can prevent restenosis and also helps when balloon angioplasty is failed.Different types of drug eluting stents (DESs) weretried in PAD patients. They were created in an attempt to overcome stent thrombosis and in-stent restenosis. ZILVERPTX trial showed that use of paclitaxel benefited much in femoro-popliteal lesions, which allowed its FDA approval in 2012 for use in PAD. [22-23]Paclitaxel has superior lipophilicity which reduces its systemic absorption and it can be applied directly over metal. This property makes it bio-compatible, and used in Bilayered stents(paclitaxel \& growth factor).Further, ongoing research on Bilayered stents (paclitaxel \& growth factor) mayhelp in improving the outcome in these patients.Platelet rich plasmacontains many growth factors like chemokines and cytokines. Thesegrowth factorshelp in wound healing by improving microcirculation and angiogenesis. In CLI patients, Use of platelet rich plasma has shown beneficial effect for limb salvage and ulcer healing process.[24-25] Deep venous arterialization (DVA) has shown promising results in patients of CLI to prevent major amputation and it is a feasible and safe alternative.[26-27]It enables wound healing by providing arterialized blood.Atherectomy evolved as an additional option in anatomic locations not normally amenable to stents, including the common femoral artery or poplitealartery. Atherectomy has become widely adopted across specialties and four main methods of function are: rotational, directional, orbital, and laser atherectomy.[28] Lithoplasty is a new technology currently under investigation.It uses same technology used in the treatment of renal calculi. It is the Shockwave Lithoplasty System (Shockwave Medical, Fremont, CA, USA. In this technology, a catheter guided balloon produces powerful acoustic shockwaves which disrupt plaques.The technology is beingstudied in the DISRUPT PAD III clinical trial.[2829]Cryoplasty Endovascular cryoplasty (Boston Scientific, Natick, MA, USA) has been introduced as an alternative to traditional angioplasty. Additional research is necessary for a better understanding of the feasibility and efficacy of advancements in angioplasty balloons (cryoplasty, laser, or vibrational angioplasty) which may help in improving the outcome in CLI patients.

\section{DECLARATIONS}

Funding: No funding sources

Conflict of interest: None declared

Ethical approval: not required

\section{REFERENCES}

. Norgren, L, Hiatt, WR, Dormandy, JA, Nehler, MR,Harris, KA, Fowkes, FG. InterSociety Consensus for theManagement of Peripheral Arterial Disease (TASC II).J Vasc Surg 2007; 45 (Suppl S): S5-S67.

2. GBD 2016 Disease and Injury Incidence and Prevalence Collaborators. Global, regional, and national incidence, prevalence, and years lived with disability for 328 diseases and injuries for 195 countries, 1990-2016: a systematic analysis for the Global diseases and injuries for 195 countries, 1990-2016: a systema
Burden of Disease Study 2016. Lancet. 2017:390:1211-1259.

3. Fowkes F, Rudan D, Rudan I, et al. Comparisonof global estimates of prevalence and risk factorsfor peripheral artery disease in 2000 and 2010: asystematic review and analysis. Lancet 2013;382:1329-40.

4. Hiatt WR. Medical treatment of peripheral arterial disease and claudication. $N$ Engl J Med.2001;344(21):1608-1621. doi:10.1056/NEJM200105243442108

Norgren L, Hiatt WR, Dormandy JA, Nehler MR, Harris KA, FowkesFG, Rutherford RB; TASC II Working Group. Inter-society consensusfor the management of peripheral arterial disease. Int Angiol.2007:26:81-157.

6. Rooke TW, Hollier LH, Osmundson PJ. The influence of sympatheticnerves on transcutaneous oxygen tension in normal and ischemic lowerextremities. Angiology. 1987;38:400-410

Sharma A. Current review with evolving management strategies in critical limb ischemia. IndianJRadiol Imaging.2019;29(3):258-263. doi:10.4103/ijri.IJRI 20819 Antithrombotic Trialists' Collaboration. Collaborative meta-analysisof randomised trials of antiplatelet therapy for prevention of death,myocardial infarction, and stroke in high risk patients. Br Med J.2002;324(7329):71-86.

9. Aiello A, Anichini R, Brocco E, et al. Treatment of peripheral arterialdisease in diabetes: a consensus of the Italian Societies of Diabetes(SID, AMD), Radiology (SIRM) and 
Vascular Endovascular Surgery(SICVE). NutrMetabCardiovasc Dis. 2014:24(4):355-369.

10. Miyashita Y, Saito S, Miyamoto A, Iida O, Nanto S. Cilostazolincreases skin perfusion pressure in severely ischemic limbs.Angiology 2011;62:15-7.

11. Setacci C, de Donato G, Teraa M, Moll FL, Ricco JB, Becker F, Robert-Ebadi H, Cao P, Eckstein HH, De Rango P, Diehm N, SchmidliJ, Dick F, Davies AH,Lepantalo M, Apelqvist J. Chapter IV: treatment of critical limb ischaemia. Eur JVascEndovasc Surg. 2011;42(suppl 2):S43-S59.

12. Bradbury AW, Ruckley CV, Fowkes FGR, et al. Bypass versus angioplastyin severe ischaemia of the leg (BASIL): multicentre, randomized controlled trial. Lancet. 2002;366(2005):1925-1934

13. Hertzer, NR, Bena, JF, Karafa, MT. A personal experiencewith direct reconstruction and extra-anatomic bypass foraortoiliofemoral occlusive disease. J Vasc Surg 2007; 45.527-535; discussion 535 .

14. Dosluoglu HH, Lall P, Cherr GS, Harris LM, Dryjski ML. Role ofsimple and complex hybrid revascularization procedures for symptomaticlower extremity occlusive disease. JVasc Surg 2010; 51:1425-1435.

15. Melliere D, Cron J, Allaire E, Desgranges P, Becquemin JP. Indicationsand benefits of simultaneous endoluminal balloon angioplastyand open surgery during elective lower limb revascularization. CardiovascSurg 1999; 7: 242-246.

16. Clement $\mathrm{C}$, Costa-Foru B, Vernon P, Nicaise H. Transluminal angioplastyperformed by the surgeon in lower limb arterial occlusivedisease: One hundred fifty cases. Ann Vasc Surg 1990; 4:519-527.

17. Dougherty, MJ, Young, LP, Calligaro, KD. One hundredtwenty-five concomitant endovascular and open proceduresfor lower extremity arterial disease. J Vasc Surg 2003; 37:316-322.

18. Dormandy J, Heeck L, Vig S. Major amputations: clinical patterns andpredictors. SeminVasc Surg. 1999;12:154-161.

19. Aulivola B, Hile CN, Hamdan AD, Sheahan MG, Veraldi JR,Skillman JJ, et al. Major lower extremity amputation: Outcome ofa modern series. Arch Surg 2004;139:395-9.

20. Stone PA, Flaherty SK, Aburahma AF, Hass SM, Jackson JM,Hayes JD, et al. Factors affecting perioperative mortality andwound-related complications following major lower extremityamputations. Ann Vasc Surg 2006;20:209-16.

21. Tateishi-Yuyama, E, Matsubara, H, Murohara, T, et al. Therapeutic angiogenesis for patients with limb ischaemiaby autologous transplantation of bone-marrow cells: a pilotstudy and a randomised controlled trial. Lancet 2002;360:427-435.

22. Dake MD, Ansel GM, Jaff MR, Ohki T, Saxon RR, Smouse HB, et al.Paclitaxel-eluting stents show superiority to balloon angioplastyand bare metal stents in femoropopliteal disease: Twelve-monthZilver PTX randomized study results. CircCardiovascInterv2011;4:495-504.

23. Dake MD, Ansel GM, Jaff MR, Ohki T, Saxon RR, Smouse HB, et al.Sustained safety and effectiveness of paclitaxel-eluting stents forfemoropopliteal lesions: 2-year follow-up from the Zilver PTXrandomized and single-arm clinical studies. J Am CollCardiol2013;61:2417-27.

24. Vicenti G, Bizzoca D, Caruso I, Nappi VS, Giancaspro G,Carrozzo M, et al. New insights into the treatment ofnon-healing diabetic foot ulcers. J BiolRegulHomeost Agents2018;32(6 Suppl. 1):15-21

25. Kontopodis N, Tavlas E, Papadopoulos G, Pantidis D, Kafetzakis A,Chalkiadakis G, et $a l$. Effectiveness of Platelet-Rich Plasmato Enhance Healing of Diabetic Foot Ulcers in Patients WithConcomitant Peripheral Arterial Disease and Critical LimbIschemia. Int J Low Extrem Wounds 2016;15:45-51

26. Del Giudice C, Van Den Heuvel D, Wille J, Mirault T, Messas E,Ferraresi R, et al. Percutaneous deep venous arterializations for severe critical limb ischemia in patients with no option ofrevascularization: Early experience from two european with no option ofrevascularization: Early exper

27. Kum S, Huizing E, Schreve MA, Ünlü C, Ferraresi R,Samarakoon LB, et al. Percutaneous deep venous arterializations in patients with critical limb ischemia. J Cardiovasc Surg (Torino)2018;59:665-9.

28. Lazar A and Morrissey N. Recent advances in endovascular treatment of peripheral arterial disease [version 1; peer review: 2 approved]. F1000Research 2020,9(F1000 Faculty Rev): 122 (https://doi.org/10.12688/f1000research.20398.1)

29. Holden A. The use of intravascular lithotripsy for the treatment of severelycalcified lower limb arterial CTOs. J Cardiovasc Surg (Torino). 2019; 60(1): 3-7. 